thoroughly researched account of the law with sufficient background material for the significance of the legal rules to be clear. To a mental health professional, the clear structure of the text, the absence of legalistic jargon and the sympathetic handling of the subject matter should make this an invaluable guide.

Despite the comprehensive nature of the Act, problems still remain. Sometimes the problems stem from ambiguity in the legislation, for example the application of the 'three month rule' under which medication cannot be administered for more than three months without either the consent of the patient or a second opinion. Sometimes they relate to matters outside the legislation, for example the application of the common law principle that information given in confidence should not be disclosed. How does this square with the view adopted by the American courts that information must be disclosed to those who may be assaulted by the patient? Similar problems apply in relation to searching a patient's person and property. It is in these grey areas of the law that ethics may play a leading role in forming opinions, directing action and ultimately, in formulating law. All are discussed in Gostin's text. On some issues, such as the type of treatment to be used, it is noted that guidance may be provided by a code of practice. On others such as the application of the three month rule, Gostin suggests a solution. On others still, such as the recently controversial issue of the sterilisation of the mentally handicapped, the author plays safe with an account of the existing case law up to 1985, the cut-off date for the text. But again, one has to emphasise that the value of the text lies not so much in specific guidance but rather in the understanding of the overall context that it provides. A practitioner would be in a much better position to make an ethical judgement having read the text. The text might not give the answer but it would at least give an accurate and understanding account of the question.

This is an excellent book, a masterly account of both law and practice and one that will be widely consulted by lawyers and practitioners alike. The only disappointment is the one identified by the author, that the European Commission on Human Rights has failed to use its opportunity to interpret the basic freedoms as including that of a right to minimally adequate treatment. Perhaps that will form the cornerstone of some future piece of legislation. The absence of Larry Gostin's campaigning spirit from these shores unfortunately makes this less likely.

TONY DUGDALE Senior Lecturer in Law Bristol University

\section{Transsexualism and Sex Reassignment}

William A W Walters and Michael W Ross, 191 pages, Melbourne, $£ 17.50$, Oxford University Press, 1986

The diagnosis, cause and treatment of transsexuality is the subject of this collection. It includes contributions from and for, nurses, surgeons, lawyers, general practitioners, social workers and psychiatrists as well as transsexuals. There is also a chapter addressing some of the ethical issues. Although geared for Australian circulation, the contents are informative, not overly technical and fulfil the book's stated aim of being an overview rather than a comprehensive textbook. In addition, it reflects some of the unresolved ethical and philosophical problems generated by the classification of transsexuality and its 'treatment' using the sex-change operation.

First, there is an absence of those objective diagnostic tests normally available to confirm or indicate the presence of pathological illness or disease. The doctor, or so it seems, can only assess the validity of the potential transsexual's claims in relation to his/ her actions and when compared with the behaviour and statements of previously 'diagnosed' 'sufferers'. This problem is further compounded by the variety of theories outlined, which suggest possible causes for transsexuality ranging from the biological to the cultural, and from psychosis to upbringing. Selection is made by matching the claims of existing clients to those of past clients for whom reassignment was successful. Not only is this an unsatisfactory method of diagnosis (though not perhaps of selection) it implies that ultimately, radical surgery is performed on the strength of the patient's self-diagnosis.

Second, the measurement of masculinity and femininity as part of the diagnosis creates philosophical difficulties. It is observed that transsexuality is most prevalent in classes, societies and cultures which adhere to rigid sex-stereotyping or roles. These same roles are, however, then used as a gauge of masculinity and femininity in transsexuals when drawing conclusions about gender adaptation and when assessing progress and success during the pre- and postoperative stages.

Even if one ignores the question of whether it is these stereotypes or the 'patient' that requires alteration, several issues remain. In the case of male to female transsexuality, (female to male transsexuality is hardly discussed being rarer, the surgical techniques employed more common and the 'patient's' transition smoother) of the supposedly feminine traits isolated, it is the most undesirable (passivity, nonassertiveness etc) which are promoted.

Also, having noted that it is general adherence to these rigid sex-roles which may be responsible for the transsexual's condition, he/she is then encouraged to adopt the opposite role in its extreme and equally oppressive form. The price, it seems, for social (and clinical) acceptability is adherence to a narrow interpretation of male and female sexuality and social expectations.

Within the context of transsexuality, the radical nature of the surgery itself poses several ethical questions. Most obvious is that of gaining fully informed consent. It is reported that the majority of patients selected for the operation are at best intermittently depressed and at worst simultaneously suffering from psychiatric illness. In either case, judgement may be impaired. Furthermore, the research results given suggest that post-operative euphoria declines over the years, meaning that complete long-term adjustment cannot be inferred from early apparent success. This uncertainty should raise the question of whether the whole procedure is still experimental and, accordingly, the ethics of permitting a steady number of operations without more research.

One might also ask why initial longterm research with a control group was not undertaken. Without such studies it is difficult to see how the patient can be informed about the potential outcome of his/her operation. In addition, the book does not satisfactorily answer criticisms that the sex-change is an attempt to treat the mind by mutilating the body. Despite the undoubted sincerity of those selected, and the obvious anguish of self-professed transsexuals in general, the fact remains that as far as it is currently possible to ascertain, there is no physical disorder present. Even the contributors recognise that transsexuality may be 
traced to that feeling associated with 'the sense of being male or female'.

Finally, the chapter on the ethical aspects of sex-reassignment and its possible consequences for the future, must be mentioned. It was beyond the scope of this collection to include a lengthy tract on the ethical issues. Nevertheless, this chapter is superficial being only an inadequate summary of the problems. It is concluded with a personal recommendation that the operations, when therapeutic, be allowed to proceed.

Unfortunately, Ross continues by urging 'extreme caution' with respect to its recipients bearing (by abdominal surgery) or adopting children. Against this recommendation it can be argued that sex-reassignment is only ethical if transsexuality is a genuine sex/gender disorder. In which case, the sufferer must be perceived as one who has, through no fault of his/her own, been 'trapped' within an unsuitable body, undergone a series of potentially dangerous, painful, therapeutic operations and has been rendered infertile as a result. Within this context it is unjust to declare that the transsexual is therefore ipso facto unsuitable to rear children, which is what Ross implies.

This publication is a reminder of the philosophical objections to current diagnostic techniques for transsexuality, and also of the ethical problems inherent in the use of the sexchange operation as a treatment for the transsexual condition. Hopefully, it will renew and broaden debate of these issues.

HEATHER DRAPER

Part-time Lecturer in Philosophy, Department of Philosophy, Crewe and Alsager College

\section{Ethical Issues in Death and Dying}

Robert $\mathrm{F}$ Weir, editor, 388 pages, New York, Columbia, $\$ 40$ hardcover $\$ 15$ paperback, Columbia University Press, 1986

In this second edition of a text originally published in 1977 the editor has incorporated several new articles together with a series of current legal (USA) examples relevant to the six sections of the book: Truth-telling; Determining and defining death; Selective non-treatment of handicapped newborns; Responsibility regarding treatment of critically ill and dying patients; Euthanasia; and Suicide.

Robert Weir is Professor of
Philosophy at Oklahoma State University where he teaches biomedical ethics. There is a wealth of information contained within this book which should assist discussion of some very basic ethical issues. By concentrating on the dying many of these issues are brought into sharp focus and the selection of articles and court cases does provide many contrasting views on each topic. For example, on truth-telling, the book looks at attitudes amongst patients and doctors and at the way in which they have changed over a sixteenyear period. Whilst many doctors may 'share the truth' in response to patient demand the grounds for doing so are still arbitrary and emotional. The complexity of deciding what a patient wants and needs to know is very well illustrated, with Weir stating that truthtelling is a moral obligation in medicine more than a mere legal requirement or doctor-controlled privilege. He gives three reasons for this: that paternalism is not a sufficient reason for withholding relevant information, that patients are autonomous people, and that the contractual nature of the doctor/patient relationship is founded on trust. Weir writes: 'The point is that patients have a right to the truth and truthfulness communicated with compassion, understandable language, empathy and respect' (page 46).

The section on determining death is interesting but based very much on the American legal situation and therefore not as readily applicable to this country. The section on treatment abatement has a lot of useful information on such areas as 'living wills', the responsibility of a doctor towards hopelessly ill people and the patient's role in decision-making. A very helpful article discusses the 'least worst death' and the ways in which respect for patient autonomy may lead to cruel results not always anticipated by those advocating 'natural death'.

The book is written by an American, for Americans, and must be seen as such. Certain words in the text might require one to reach for the dictionary (USA edition) for clarification (for example 'fiduciary' and 'egregious'). However, it is a useful publication for those who wish to have easier access to some of the legal decisions made in recent years which have affected clinical practice in America and which might influence practice in this country in the next few years.

PETER SPECK Chaplain, Royal Free Hospital London
Care of the Handicapped Newborn: Parental Responsibility and Medical Responsibility

The Catholic Bishops' Joint Committee on Bio-ethical Issues, 19 pages, London, 60p, The Catholic Media Office, 1986

Most mothers dread the possibility of bearing an abnormal baby. The reality of coping with this event is the subject of this booklet which addresses the bioethical management issues which are raised. It is the product of a multidisciplinary working party of the Roman Catholic Church. The underlying assumption of the discussion is the equality of human rights of every baby to the care and support of the community in which he or she is born. An argument is developed to support the contention that it is an illusion to think that judgements about the worthwhileness of a patient's life can form the basis for clinical treatment. Thus the emphasis of the authors is unequivocally to avoid any situation in which the primary object of management decisions results in any hastening of a child's death.

There are sections on the status of the newborn, and the nature of treatments available, discussing the factors which would need to be taken into account in deciding whether or not treatment would be of benefit to a particular baby. Several questions are clearly outlined. They include the burdensome character of some therapies, the realistic prognosis for the child, and the relative availability of resources, be they financial or medical and nursing expertise. Several specific disorders are described in relation to the management strategies adopted; a useful glossary of medical terminology is provided. Spina bifida and Down's syndrome are two conditions which are examined in closer detail since they are frequently encountered. This is a subject area which arouses deep emotions and it is not unusual for many of those involved to experience genuine differences of opinion. Advice is given for some specific situations such as where parents feel their child's rights are not being respected; the paediatrician faced with parents who reject their handicapped child, and the nurse who regards her instructions as being immoral.

The booklet ends with a section on the role of the Church and society, emphasising the dignity of humanity and 